\title{
About hypothermal J wave
}

\author{
prof. Andrés Ricardo Pérez Riera, $M D$, PhD
}

Cardiology Discipline, Electrovectorcardiogram Sector, ABC Faculty of Medicine, ABC Foundation, Santo André, Sâo Paulo, Brazil



A typical electrocardiogram feature of the hypothermal state is the appearance of a very characteristic extra wave, called the J wave, 'camel hump-sign', 'hump-like deflection', 'injury potential', 'late $\delta$ wave' and by the unjust eponym Osborn wave [1]. It is located at the point where QRS ends and the initial portion of ST segment. It corresponds to phases 1 and 2 of monophasic action potential (AP) of cardiomyocytes. The J wave is characteristic of hypothermia; however, it is not pathognomonic, since it may be observed in other normothermic conditions. The J wave presents the following features:

LOCATION: It starts where the QRS complex ends (late $\delta$ wave), occupying the initial portion of the ST segment, corresponding to phases 1 and 2 of monophasic AP of cardiomyocytes [1].

POLARITY: Always positive and prominent in the leads that face the left ventricle: $V_{5}$ and $V_{6}$ and possibly and mainly in hearts in a vertical position in inferior wall leads [2], differently from the $\mathrm{J}$ wave found in Brugada syndrome, located in right precordial leads.

VOLTAGE: Slow and lasting inscription, and voltage greater in left leads $\mathrm{V}_{5}$ and $\mathrm{V}_{6}$ and inversely proportional to the severity of hypothermia, i.e. the lower the central temperature, the greater the voltage of J wave. In certain cases, J wave acquires a great voltage associated with superior convexity, mimicking the acute phase of myocardial infarction: 'evolving myocardial infarction', which reverses with central temperature normalisation [3]. There is inverse and significant correlation between J wave voltage [mm] and central temperature in hypothermia.

ASPECT: It may resemble a small secondary $R$ wave $\left(R^{\prime}\right)$, falsely mimicking right bundle branch block or left bundle branch block. The J wave is characteristic of hypothermia; however, it is not pathognomonic, since it may observed in normothermic circumstances $[4,5]$ such as hypercalcaemia [6], subarachnoid haemorrhage [7], Brugada syndrome [8], Brugada phenocopies [9], concealed forms of arrhythmogenic right ventricular cardiomyopathy/dysplasia [10], early repolarisation variant [11], and Prinzmetal variant angina [12].

Electrophysiological substrate of J wave: Experimental studies point out that J wave appearance is the consequence of the presence of transmural gradient in ventricular wall thickness, secondary to the existence in the epicardium, but not the endocardium, of significant notch in phase 1 mediated by a greater activity or density of initial transient outward potassium current. This greater activity and/or density of the Ito channel in epicardial cardiomyocytes, but not endocardial ones, accounts for the characteristic aspect of AP known as 'spike-and-dome configuration of the monophasic $\mathrm{AP}^{2}$. Moreover, the greater initial potassium outflow in the epicardium than the endocardium, causes phase 2 shortening in the epicardium, which conditions transmural dispersion of repolarisation and J wave appearance, which, carried to a certain level, causes a greater tendency to the appearance of ventricular arrhythmia by the mechanism called functional reentry in phase 2 [12].

Main electrocardiographic changes in hypothermia:

(1) Sinus bradycardia in the initial phase; there may be tachycardia by release of adrenaline.

(2) Artifacts: frequent fluctuation in the baseline as a consequence of artifact caused by the muscular trembling of the patient. This fact is found only in the initial phase (of struggle), when body temperature is between $36^{\circ} \mathrm{C}$ and $32^{\circ} \mathrm{C}$.

(3) Widening of $\mathrm{P}$ wave (decreasing of the velocity of intraatrial conduction). Also in $\mathrm{P}-\mathrm{a}$ decrease in voltage is described in around $50 \%$ of the cases when temperature reaches $25^{\circ} \mathrm{C}$.

(4) Prolongation of PQ interval: it tends to be prolonged as body temperature decreases [13].

(5) QRS complex: a decrease is verified in voltage and increase in duration of profound hypothermia ( $>$ QRSD). Moderate hypothermia affects only ventricular repolarisation and may not affect ventricular depolarisation. QRS prolongation may be mistakenly considered longer by an erroneous inclusion of the J wave as part of the QRS complex, and QRS simulating a branch block or intraventricular disorder of the stimulus. The explanation for QRS prolongation is in the decrease of the rest potential and consequently of the ascension velocity of phase 0 , and subsequent lower velocity of dromotropism conduction. When a rapidly induced hypothermia for cardiac surgery extends the QRS complex, it causes ventricular fibrillation in almost all the patients $[14,15]$.

(6) Widening of QRS (decreasing of the velocity of intraventricular conduction) resulting in nonspecific or unspecified intraventricular conduction disturbance. QRS complex: decrease in voltage and increase in duration. The latter may be mistakenly considered to be increased, by the presence of the 
so-called J wave (see item as belonging to QRS), resembling branch block or unspecific intraventricular conduction defect. The explanation for QRS broadening is in the decrease of rest potential and consequently, phase 0 rise velocity and negative dromotropism across all depolarisation process.

(7) J wave. Why remove the eponym Osborn's wave? Because we see the eponymous denomination, the Osborn wave, as an unfair choice, since the first to describe it was Tomaszewski [16]. Five years after the first description, the Germans Grosse-Brockhoff and Schoedel described it in an experimental work [17]. The description by Osborn happened 15 years later, in 1953 [18]. Ironically, valuable Cardiology texts called the wave Osborne, adding an 'e' vowel to the surname of the author [19].

(8) Widening and flattening of T waves.

(9) Prolongation of QT/QTc intervals.

(10) Arrhythmias: atrial fibrillation and ventricular fibrillation. Ventricular fibrillation has great possibilities of appearing with temperatures below $28^{\circ} \mathrm{C}$. When it occurs with values above $28^{\circ} \mathrm{C}$, associated myocardial disease must be suspected.

Conflict of interest: none declared

\section{References}

1. Alsafwah S. Electrocardiographic changes in hypothermia. Heart Lung, 2001; 30: 161-163.

2. Sgobba G, Nassisi G, Giannelli F et al. Electrocardiographic changes in accidental hypothermia. G Ital Cardiol, 1982; 12: 147-150.

3. Sain T, Bharani A. Post-trauma electrocardiogram mimicking myocardial infarction. J Assoc Physicians India, 2002; 50: 834-835.

4. Burali A, Porciello PI. Osborn wave in normothermic patients? G Ital Cardiol, 1991; 21: 1005-1009.

5. Patel A, Getsos JP, Moussa G et al. The Osborn wave of hypothermia in normothermic patients. Clin Cardiol, 1994; 17: 273-276.
6. Okada M. The cardiac rhythm in accidental hypotermia. J Electrocardiol, 1984; 17: 123-128.

7. Topsakal R, Sağlam H, Arinç H et al. Electrocardiographic J wave as a result of hypercalcemia aggravated by thiazide diuretics in a case of primary hyperparathyroidism. Jpn Heart J, 2003; 44: 1033-1037.

8. Carrillo-Esper R, Limón-Camacho L, Vallejo-Mora HL et al. Non-hypothermic J wave in subarachnoid hemorrhage. Cir Cir, 2004; 72: 125-129.

9. Baranchuk A, Nguyen T, Ryu MH et al. Brugada phenocopy: new terminology and proposed classification. Ann Noninvasive Electrocardiol, 2012; 17: 1-16.

10. Corrado D, Nava A, Buja G et al. Familial cardiomyopathy underlies syndrome of right bundle branch block, ST segment elevation and sudden death. J Am Coll Cardiol, 1996; 27: 443-448.

11. McIntyre WF, Pérez-Riera AR, Femenía F, Baranchuk A. Coexisting early repolarization pattern and Brugada syndrome: recognition of potentially overlapping entities. J Electrocardiol, 2012; 45: 195-198.

12. Aizawa Y, Sato A. Brugada syndrome and vasospasitc angina do coexist: potential clinical importance. Intern Med, 2006; 45: 43-44.

13. Yan GX, Antzelevitch C. Cellular basis for the electrocardiographic J wave. Circulation, 1996; 93: 372-379.

14. Emslie-Smith D, Sladden GE, Stirling GR. The significance of changes in the electrocardiogram in hypothermia. Br Heart J, 1959; $21: 343$

15. Fleming PR, Muir FH. Electrocardiographic changes in induced hypothermia in man. Br Heart J, 1957; 19: 59-66.

16. Tomaszewski W. Changements electrocardiographiques observes ches un homme mort de froid. Arch Mal Coeur, 1938; 31: $525-528$.

17. Grosse-Brockhoff F, Schoedel W. Das Bild der akuten Unterkuhlung in Tierexperiment. Arch Exp Pathol Phramakol, 1943; 201: 417.

18. Osborn JJ. Experimental hypothermia: respiratory and blood $\mathrm{pH}$ changes in relation to cardiac function. Am J Physiol, 1953; 175: 388-398.

19. Braunwald E. Heart disease. A texbook of cardiovascular medicine. 5th Ed. Lippincott Williams \& Wilkins, Philadelphia, PA 1997. 